\title{
El perfil del turista internacional de Cozumel a partir de la construcción de su capital simbólico
}

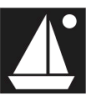

\author{
Julia Sderis Anaya Ortiz \\ Alejandro Palafox Muñoz \\ Universidad de Quintana Roo, \\ Unidad Académica Cozumel \\ División de Desarrollo Sustentable
}

\section{RESUMEN}

La isla de Cozumel recibe más de dos millones de turistas al año, principalmente de los países vecinos del Norte. Si bien las investigaciones realizadas por la federación establecen diferencias geográficas, las motivaciones de los visitantes pueden ser distinguidas al examinar su capital simbólico, que permite descifrar el perfil de los turistas internacionales que arriban a la ínsula. Para determinar lo anterior fue necesario estudiar sus capitales económico, social, cultural y simbólico, lo cual, en la práctica turística de los individuos, se expresa de manera diferenciada en la elección de las actividades o la motivación para visitar cualquier destino. Por medio de la aplicación de encuestas en las salas del Aeropuerto Internacional de Cozumel, y de un análisis deductivo, se detectaron las particularidades de los turistas. El análisis indica que el turista internacional que visita Cozumel convive y experimenta sensaciones de satisfacción y bienestar al relacionarse con los residentes del destino, tanto en su rol de prestadores de servicios turísticos como de nativos interactuando en el mismo espacio social.

\footnotetext{
Palabras

CLAVE Capital simbólico, perfil del turista, Cozumel
} 


\section{Introducción}

Cozumel es una isla localizada en el Caribe en la que se desarrolla el turismo como actividad económica básica, a partir de los atractivos culturales y naturales con los que cuenta; entre los primeros están la fiesta del Carnaval, la fiesta de El Cedral o de la Santa Cruz, la fiesta de San Miguel -que se conmemora en honor del santo patrono del pueblo- y la fiesta del Día de Muertos; mientras que entre los segundos se encuentran, por ejemplo, los arrecifes coralinos, que la convierten en uno de los sitios de buceo de mayor renombre en el mundo. Estos atractivos motivan a diferentes tipos de turistas en grandes y pequeños grupos, quienes llegan a la isla por diversos medios: crucero, avión, ferry y transbordador. Según los reportes provistos por la Secretaría de Turismo del Estado de Quintana Roo (Sedetur, 2009), en 2008 Cozumel recibió 92445I turistas, que produjeron una derrama económica de 497354638 dólares, a partir de un gasto turístico promedio de 538 dólares americanos por turista. Es pertinente resaltar que la cifra no considera el gasto realizado por los excursionistas de cruceros, quienes en forma masiva constituyen la mayor corriente turística de la isla (2569433 turistas) con un gasto de 82 dólares por persona. Para efectos de esta investigación se estudiará únicamente al turista que pernocta en la isla.

Para la satisfacción de estas corrientes turísticas existe una red de servicios conformada por la zona hotelera norte, centro y sur. Cozumel cuenta con 51 hoteles y 4373 cuartos, respaldados por una infraestructura que, además de proveer servicios al poblado, apoya a restaurantes, bares, espectáculos, excursiones, transportación, telecomunicaciones, entre otros. La diversidad de grupos que constituyen el turismo que llega a Cozumel consume diferentes productos y servicios dependiendo de sus gustos y necesidades, por lo que se establece que no existen grupos homogéneos de consumo, lo cual genera los cuestionamientos: ison las delimitantes económicas, culturales, sociales, regionales, las que influyen en la compra del destino?, ¿de qué manera interviene el capital simbólico en la configuración del perfil del turista internacional en Cozumel?, y la necesidad de las empresas de servicios turísticos, gubernamentales, organizaciones no gubernamentales y de todas aquellas que interactúan con la corriente turística actual de estudiarla para saber qué ofrecerle.

El propósito de la investigación es analizar el perfil del turista internacional que arriba a Cozumel, con la finalidad de proporcionar información referente 
a sus gustos, hábitos y preferencias, con base en el estudio de su cultura, la cual, según la teoría de Pierre Bourdieu (200I), se integra a partir de sus capitales social, económico, cultural y simbólico, los cuales se ven reflejados en su práctica turística (en el consumo, en las relaciones sociales y los simbolismos, que son definitivos en la decisión de compra).

En este documento se examina el perfil del turista internacional desde el concepto de capital simbólico, pues se considera que éste ha sido el menos trabajado en materia turística y el que influye de manera definitiva en la práctica turística, y, por lo tanto, delimita el perfil del turista. Sin embargo, también se revisan los capitales económico, social y cultural, a partir de las investigaciones y trabajos descriptivos que se han generado en universidades y diversas instituciones nacionales e internacionales dedicadas al estudio del fenómeno turístico. Esto es fundamental, ya que al no incluir los demás capitales el estudio estaría incompleto, porque los simbolismos son parte de la cultura del individuo e inherentes a sus rasgos económicos y sociales.

Bourdieu aporta al estudio de las sociedades su teoría de los campos y da a los actores sociales, a sus prácticas y a sus formas de organizarse, un nuevo sentido determinado no solamente por el grupo social homogéneo al que pertenecen por su capacidad económica; él los analiza y los agrupa desde sus características culturales, abordando conceptos como habitus,' campos culturales, lucha de clases, mercados culturales, espacio social y capitales, sin desdeñar las delimitantes económicas o de consumo.A partir de información generada y de su sistematización, la sociedad conocerá el perfil del turista internacional que llega a la isla de Cozumel, así como el del turista potencial, por lo que servirá como herramienta para establecer las estrategias necesarias dirigidas a la creación o renovación de sus productos, servicios y procesos, lo cual, a su vez, satisfará los requerimientos de los turistas, además de reportar beneficios como la repetitividad en la visita al destino, favoreciendo a las localidades que logren relacionarse con esta corriente turística.

\footnotetext{
' Es la adquisición de las características individuales de los actores a través de la vida diaria y sus vivencias en el entorno donde se han desarrollado.
} 


\section{Marco teórico: los capitales y los campos culturales}

El individuo, a lo largo de su vida, acumula experiencias, conocimientos y habilidades, que conforman en él capitales, los cuales le permiten agruparse con otros individuos con características comunes, de manera que constituyen campos, entendidos como el conjunto de propiedades con que las personas organizan sus acciones y con las que pueden negociar; éstas les otorgan algún tipo de beneficios o capacidades, alrededor de los cuales se forman competencias, que a su vez permitirán a cierto grupo obtener un lugar o posición en el espacio social, ${ }^{2}$ de quien detenta el capital y de quienes aspiran a poseerlo. De este modo, cada individuo puede pertenecer a diferentes campos según la conformación de sus capitales, que pueden ser objetivos (materiales, por ejemplo el capital económico: casas, autos, dinero) o subjetivos (como el capital cultural), que están incorporados, por ejemplo un título escolar que da validez a los conocimientos.

Para Bourdieu ( 199 I), los capitales funcionan simbólicamente, determinan un estilo de vida, proporcionan el reconocimiento social y en ese momento se crea una distinción entre los individuos y grupos. Los capitales pueden ser dinámicos, ya que existe lo que Bourdieu llama un campo de fuerzas: el individuo pone en juego sus capitales con otros individuos y los desarrolla en un campo en el cual se transforman, lo que significa que en cada campo existe una lucha por apropiarse del capital. Por ejemplo, en el campo turístico, en el que dos familias salen de vacaciones, el dinamismo de los capitales se deja ver en el momento en que deciden cuál será el destino, cuál será el mejor lugar para hospedarse, cuáles serán los lugares de recreo y dónde se hará el consumo de alimentos; de esa forma se pondrá de manifiesto la lucha por legitimar las acciones y deseos de las familias. Las luchas de poder dentro de los campos se dan en un espacio social en el que el individuo debe moverse relacionándose con diferentes grupos de acuerdo con sus intereses. Sin embargo para Bourdieu es un sistema de posiciones sociales relativas, que se definen unas en relación con

${ }^{2}$ El espacio social es donde los individuos se desarrollan e interactúan y ponen en juego sus habilidades y aptitudes en áreas específicas (capitales). Estos espacios sociales y de relaciones se dan en el trabajo, la escuela, el ámbito familiar y muchos otros espacios en los que el individuo suela encontrarse; el turismo es uno de ellos.

TeOría y Praxis

8 (2010: I7I- |85) 
las otras, cada posición tiene un valor (que mide la distancia social) y se puede presentar en forma de espacios construidos con base en principios de diferenciación o distribución de propiedades que confieren poder a quien las posea (Bourdieu, I99I cit. en Zizumbo Villareal, 1999).

En este sentido, el espacio social turístico es donde los individuos llevan a cabo sus prácticas turísticas, como una agencia de viajes, un bar, un museo, una playa, un centro recreativo, una zona arqueológica, un hotel, incluso el mismo grupo de amigos en el que se discute cuáles son los mejores lugares para visitar en el destino. La práctica turística se da en función de los requerimientos de cada grupo social, ésta varía de acuerdo con el campo al que se integre según la configuración de sus capitales y a su actuación en los espacios sociales turísticos que le interesen, integrándose a éstos en diferentes caracterizaciones según sus demandas, es decir, puede presentarse como posible viajero al pedir informes acerca de un destino, como turista en algún recorrido, o como consumidor en su propio lugar de origen al abastecerse de objetos para el viaje; de esta forma se conjunta la variedad de capitales individuales, con los que se discuten e intercambian ideas y puntos de vista acerca del turismo, deviniendo una práctica turística con un perfil específico.

En el turismo, el individuo que haya recibido la influencia de un mercado turístico específico determinará su propia visión de la realidad en la práctica, de modo que los mercados culturales constituidos para el turismo se establecen en el sentido de sus preferencias o inclinaciones que, según los capitales de cada persona, se manifestarán de diferentes maneras, reflejándose en sus actividades diarias y cotidianas.Así, los individuos van a manifestar sus necesidades, lo que permite que la práctica turística tome distintas formas, aun cuando se lleve a cabo en un mismo destino. De tal suerte, las prácticas turísticas son delimitadas por las pautas culturales de cada grupo social.Ya que la vida social se reproduce en los campos (económico, político, científico, cultural, simbólico), éstos construyen un sistema de relaciones entre los agentes sociales que intervienen directamente en ellos; cada campo está constituido por un capital común y por la lucha por su apropiación.

De acuerdo con Pavón Santana (1999), la práctica turística es considerada como todas aquellas actividades recreativas y de esparcimiento que realizan los individuos en los diferentes destinos de interés turístico. De esta manera, los turistas manifiestan su perspectiva, lo que les permite adoptar diversos matices -incluso si esta práctica se lleva a cabo en un mismo lugar-, debido a los 
hábitos que el individuo ha acumulado y adquirido por los distintos medios en los que se ha desenvuelto, afectando la forma en que visualiza el mundo, así como las relaciones familiares, las condiciones económicas, el nivel escolar, la ideología, los intereses, los gustos, y cualquier otra situación que haya experimentado en cada etapa de su vida. Lo anterior configura las prácticas culturales de todo individuo. Entonces, el capital cultural se "manifiesta de manera expresa mediante la escolarización, capacitación, diplomas y títulos. La educación permite llegar a límites insospechados, que en su buen uso es una herramienta de trabajo y distinción” (Pavón Santana, 1999: I54).

Por otro lado, el capital social está fundamentado en la pertenencia a un círculo social en el que, para mantener el orden, los miembros deben acatar normas; además, está respaldado por el grupo en sus intereses mutuos, que de algún modo están institucionalizados o reconocidos, lo cual les permite adquirir beneficios, apoyos, garantías e influencias de otras instituciones o grupos. Asimismo se entienden las reciprocidades materiales y simbólicas, es decir, se hace referencia a la confianza entre sujetos que pertenecen al mismo grupo social; al cuidado y la preocupación mutua; a la voluntad de los sujetos para vivir conforme a las reglas del grupo social del que forman parte (Schuller, 2000); por lo tanto, adquieren algún tipo de capital simbólico por el solo hecho de pertenecer.

En la práctica turística se desarrollan las relaciones entre visitantes y comunidad receptora. Esta condición respalda y proporciona prestigio, respeto, influencia, reputación y autoridad en determinados temas a aquellas personas que pertenecen a alguna organización. Por ejemplo, el Instituto Nacional de la Senectud (Insen) apoya a las personas de la tercera edad al tramitarles descuentos especiales en transportación, hospedaje y compra de artículos en algunas tiendas, así como al ofrecerles atención especial de algunas empresas de servicios turísticos, como servicios médicos en los transportes, sólo por pertenecer a ese grupo.

El conjunto de recursos y bienes del que disponen las personas (los ingresos económicos que se obtienen del trabajo y de los diversos movimientos financieros de cada individuo, la frecuencia con que gasta y la calidad del consumo) representan el capital económico. Un individuo accederá a su práctica turística dependiendo de su habitus; reservará una habitación con anticipación, comprará un boleto de avión en primera clase, viajará al extranjero, le pagará 
a un agente de viajes para que le organice sus vacaciones, incluso adquirirá artículos adecuados para el tipo de turismo que se llevará a cabo: equipo de buceo, cremas bronceadoras, maletas, ropa, etcétera.

Como puede observarse, la actividad turística está multideterminada y sólo puede ser explicada a partir de un análisis que vincule elementos económicos y culturales. Si bien toma del marxismo la idea de una sociedad estructurada en clases sociales en permanente lucha por la imposición de sus intereses específicos, entiende que las diferencias económicas y materiales no son suficientes para explicar la dinámica social. El poder económico sólo puede reproducirse si, al mismo tiempo, logra hegemonizar el poder cultural y ejercer poder simbólico (Degl' Innocenti, 2007). Para realizar un análisis del capital simbólico es necesario hacer uso de los capitales cultural, social y económico, ya que son inherentes a las acciones del hombre, sin embargo lo simbólico es el resultado de la integración de los demás capitales en la vida del individuo. En el caso del turismo, éste otorga un reconocimiento, que es avalado por la sociedad, brindándole a la persona una posición de valor o poder representativo en su entorno social. El capital simbólico es una propiedad con la que cuenta el individuo, como la fuerza física, la belleza, la riqueza, la sabiduría, la pertenencia a algún grupo; es en general el honor y el prestigio que cualquier tipo de capital le otorga a la persona, una afirmación ante la sociedad; por tanto, es la capacidad de consagrar y de que se reconozca como propio o legítimo lo que se hace, se consume, se usa, se propone, sin necesidad de ser cuestionado; es aquí donde se transforman los capitales, de manera que cada uno de ellos es reconocido por la sociedad hasta convertirse en un símbolo. Por esto el individuo en sí, ya incluido en el grupo del perfil del turista internacional, simbólicamente representa un grupo reconocido y delimitado por sus acciones específicas y que, además, dentro de su grupo, también lucha por detentar el poder en sus acciones.

En el ámbito turístico, el capital simbólico es observable en hechos como practicar golf, portar una tarjeta de crédito que posea algún determinado extracto social, ser cliente VIP, platicar sobre la visita a algún destino turístico al que pocas personas han ido y se ha convertido en un lugar de moda que sólo algunas personas con un determinado nivel económico conocen, comprar recuerdos que acrediten el viaje o mostrar fotografías de las actividades que se llevaron a cabo y que no son del dominio de todos. Ese tipo de actividades 
son las que diferencian a las personas y aportan distinción y reconocimiento, incluso dentro de un grupo social en un mismo destino turístico.

\section{Metodología}

Por lo anterior, "el conocimiento científico del turismo ha estado aunado al avance que han tenido las ciencias sociales. Desde la concepción que se tiene de turismo, ha estado orientado a dar respuesta a los intereses de la política turística, a resolver problemas.

A través de un método analítico-interpretativo, bajo un esquema deductivo, se analizan los capitales económico, social, cultural y simbólico, con énfasis en este último. El examen de los tres primeros fue factible mediante el acceso a documentos descriptivos ya elaborados, que generaron resultados similares a los reunidos en el levantamiento de los datos en los cuales se soportó el análisis. Empero, por el carácter subjetivo de las representaciones sociales colectivas que pueden ser cambiantes y por el desconocimiento de la importancia y el beneficio que pudiera tener este factor en el aspecto económico, lo simbólico del perfil del turista internacional se ha tratado escasamente. La investigación utilizó como instrumentos de investigación de campo encuestas elaboradas con base en los criterios que establece la teoría de los capitales, aplicadas a turistas en la sala de espera del Aeropuerto Internacional de Cozumel, antes de su salida del país, al documentar su equipaje. Para determinar el número de encuestas, se efectuó un muestreo probabilístico tomando como referencia la cantidad de turistas que visitaron la isla en 2008 , con base en la fórmula para el cálculo de muestras para poblaciones finitas, con un error de estimación de cinco por ciento, obteniendo una muestra de 384 encuestados. Después de concentrar la información se realizó el análisis contrastando la teoría con la información recogida en el trabajo de campo, para finalizar la investigación con la redacción de las conclusiones.

\section{Resultados}

El habitus hace que personas de un entorno social homogéneo tiendan a compartir estilos de vida parecidos tanto en la cotidianidad como en los momentos de ocio. Por ello, alrededor de las necesidades se configura una serie 
de fenómenos sociales, económicos, políticos y culturales tanto en el destino emisor como en el receptor, lo cual resalta la importancia de conocer el perfil del turista y saber a ciencia cierta de qué manera se articulan sus campos culturales y cuáles sus necesidades, para encontrar la forma de atenderlas. Esto se logra analizando sus campos culturales y la conformación de su habitus.

No obstante, en la predisposición al consumo turístico, existen otras influencias como la sugestión de los medios de comunicación. Al respecto, Bourdieu (1997) no cree que la presión del mercado y de las audiencias sea una expresión determinante del discurso de los medios, sino que son las personas quienes detentan el poder de decisión de difusión de la información, es decir, que son quienes intervienen sobre las necesidades de consumo, y a la larga son parte de la conformación de sus capitales y, por ende, de la decisión de llevar a cabo determinadas prácticas turísticas. También afirma que lo real es relacional (la descontextualización de cualquier descripción y análisis que se haga de un grupo es un ejercicio vano y erróneo, porque el grupo actúa en un momento y espacio social determinado que condiciona el campo de lo posible) y que lo relacional conduce a la distinción, a la diferencia. Los rasgos distintivos sólo existen cuando se ponen en relación con otras propiedades.

Por tanto, cuando se habla del capital simbólico del turista internacional de Cozumel, se alude a los estadounidenses y canadienses. Aquí se hará énfasis en las especificidades de los segundos, ya que suelen ser muy parecidos a sus vecinos del sur en cuanto a su capital económico y al consumo de servicios, que se rigen por la apertura del libre comercio entre ambos países y el acceso a la información, entre otras cosas. Sin embargo, sus motivaciones culturales del viaje hacen la diferencia, por lo que no se puede afirmar que todos los turistas internacionales que llegan a Cozumel son poseedores de un capital simbólico homogéneo.

En primera instancia, los turistas estadounidenses constituyen una corriente turística estable en México, y así lo son para Cozumel, pues constituyen 88 por ciento de la demanda turística internacional de la isla. Su consumo de viaje es a partir de la fortaleza de su moneda, pues su país cuenta con una economía firme, recursos naturales y una infraestructura moderna y tecnológica que les permite estar un paso adelante en la información y, por consecuencia, en conexión con el mundo. Sus prácticas turísticas están determinadas con base en sus capitales culturales, los cuales se constituyen posteriormente en símbolos, como en el caso del conocimiento intelectual, colocándolos en un grupo 
seleccionado que les otorga un sentido de pertenencia, lo que genera un prestigio tanto de su nivel intelectual como de su capacidad económica, haciendo que la sociedad los reconozca como símbolos de lo que se aspira a ser o pertenecer.

Su capital cultural se caracteriza porque en su mayoría cuentan con estudios de educación superior, lo que los habilita para desempeñarse en actividades profesionales como profesores; en las ventas en diferentes modalidades y en puestos gerenciales; como supervisores o como propietarios de sus negocios; es decir, son líderes en su campo laboral, situación que puede ser decisiva para la reproducción de prácticas turísticas interpretadas como legítimas entre sus grupos de referencia.

En cuanto a su capital social, son un grupo con un alto grado de alfabetización (97 por ciento) y cuentan con una fuerte identidad social entre los grupos culturales que conforman su población. Estados Unidos y Canadá se han convertido en países de "tolerancia racial" y se han integrado como comunidad y en todas las actividades, lo que ha permitido a sus ciudadanos realizar viajes de índole turística.

Ambos países tienen una cultura del consumo, por ello quienes viajan a Cozumel también se desplazan a otros sitios dentro del territorio mexicano, motivados por el clima, las playas, las compras y la cultura, y porque se han legitimado como destinos obligados cuando se visita México, lo que les proporcionan satisfacciones y significaciones similares a las que les ofrece Cozumel, pero con el elemento adicional de que son reconocidos en el mundo como etiquetas del paraíso o símbolos de la cultura, por lo tanto se dirigen principalmente a Chichén-Itzá, Tulum y Cancún. Asimismo dicen que regresarían a Cozumel y desde ahí viajarían a Vallarta,Acapulco y la Riviera Maya.

Cabe hacer énfasis en que la mayoría de los individuos viajan en pareja -algunos se hospedan con la familia-y no tienen experiencia en buceo, por lo que prefieren la seguridad de una actividad que no implique riesgos. Si se establece que entre sus preferencias los estadounidenses consideran a las playas y los arrecifes puede interpretarse que cuentan con un alto capital económico pero con un bajo capital cultural, dado que en general no están interesados en conocer la cultura maya o la del destino, sin embargo las ubican como parte importante del lugar, viéndolas como un atractivo más.

Con base en lo dicho, la experiencia turística en Cozumel simboliza la sensación de gusto en cuanto a la percepción del servicio y el contacto con los 
residentes del pueblo, además se experimenta un sentido de felicidad, satisfacción y, en algunos casos en su lugar de origen, se genera un sentido de envidia, reconocimiento entre sus familias, amigos y conocidos sobre las vacaciones en Cozumel. Este turista obtiene información sobre Cozumel a través de los diferentes medios de comunicación que ha elegido con base en su capital cultural y sus expectativas de viaje.Así, internet se establece como fuente primaria de información, instrumento que se convierte en una forma verídica y legítima entre los integrantes de su campo cultural turístico, es decir, los individuos que se mueven en ese campo llegan a un consenso de lo que es el viaje, lo cual contribuye a la reproducción social de las prácticas turísticas. En este sentido, el papel que juegan los medios en la promoción del destino contribuye de manera importante en la decisión del viaje $y$, de forma simbólica, controla la información.

Al respecto, Bourdieu (2000) afirma que no es suficiente señalar que las relaciones de comunicación son siempre, inseparablemente, relaciones de poder que dependen en su forma y contenido del poder material o simbólico acumulado por los agentes (o las instituciones) comprometidos en esas relaciones y que pueden permitir acumular poder simbólico; en cuanto instrumentos estructurados y estructurantes de comunicación y de conocimiento, los sistemas simbólicos funcionan como instrumentos para imponer y legitimar la dominación que contribuye a asegurar la supremacía de una clase sobre otra (violencia simbólica), aportando su propia fortaleza a las relaciones de fuerza que las fundan, favoreciendo así "la domesticación de los dominados" (Weber, 1964).

Las motivaciones e intereses de los turistas estadounidenses que arriban a Cozumel son particularmente el descanso, la recreación y la confirmación de sus actividades sociales, ya que en el viaje hay mayor comunicación con sus familiares que en la vida diaria, y después de éste logran distinguirse e influir en los integrantes de su círculo social para motivar la visita el destino. Prefieren alojarse en hoteles de cuatro o cinco estrellas, con tendencia hacia el all inclusive, sin embargo, un elemento decisivo es la ubicación del hotel, ya que con base en ello determinan los demás factores que les permitan cumplir con sus expectativas, por ejemplo estar cerca de la playa o del pueblo. La paridad peso-dólar incrementa su capital económico en el momento, por lo que el precio y la marca son importantes en la toma de decisiones, de modo que la mayoría de los turistas consume sus alimentos en el hotel. 
En virtud de su capital económico, estos turistas tienen la posibilidad de incrementar su capital simbólico al insertarse en un campo cultural que no es el habitual, lo que no sucede con su capital cultural (que sigue siendo bajo). Para ellos no es tan importante platicar con su grupo social sobre su convivencia con los residentes, pero requieren legitimar la visita mediante objetos con íconos o imágenes de Cozumel y artículos que representen su viaje:sombreros, cobijas, salsas; por su parte, la compra de joyas les permitirá detentar el poder de su campo económico al objetivar su actividad turística a partir de esos objetos, lo cual, simbólicamente, los consagrará como práctica legítima dentro de su grupo social.

A diferencia del de los estadounidenses, el capital social de los canadienses tiene una fuerte identidad basada en características culturales, que se originan en la monarquía inglesa que a la fecha prevalece mediante la representación de una reina que, aunque no administra el país, influye en las decisiones del Estado, circunstancia que contribuye a conservar el capital económico y simbólico del país entre sus residentes y en su imagen ante el mundo. Asimismo, cuentan con la libertad de la democracia, en la que es posible elegir a sus representantes, y como resultado de su devenir histórico es oficial el uso de dos idiomas: inglés y francés.

Un capital económico obtenido de una economía orientada al mercado y una moneda fuerte les permite tener altas expectativas con relación al servicio esperado, ya que el sector turismo de su país ocupa el segundo lugar en el nivel mundial en cuanto a calidad, constituyéndose en una fortaleza para ellos y en una debilidad para los países en desarrollo, pues, al igual que en Estados Unidos, se registran altos índices de turismo interno, apoyados en el desarrollo de sus comunicaciones y en la oferta de los recursos turísticos que poseen.

Sus viajes son más prolongados y aprovechados por el destino que los acoge; cuentan con un gran capital cultural: 97 por ciento de su población está alfabetizada y tiene una alta capacidad adquisitiva; 84 por ciento ha realizado estudios superiores; están dispuestos a pagar entre I 500 y 3000 dólares canadienses en destinos turísticos con variedad de recursos naturales y áreas protegidas, ya que presentan una fuerte tendencia hacia lo natural, conocen la historia, la situación actual y la condición de los recursos del lugar que visitarán. Los interesados en el turismo de aventura son personas de entre 24 y 54 años y sus viajes duran más de dos semanas. Los grupos de canadienses están constituidos 
regularmente por adultos y adultos mayores, quienes realizan los viajes internacionales y les atrae la música, el teatro, las zonas arqueológicas, el folclore y la gastronomía local. Del mismo modo que los estadounidenses, buscan la recreación y el descanso en destinos de sol y playa prefiriendo el Caribe; no 183 obstante, sus viajes de largo plazo son por lo general a Europa, donde visitan principalmente destinos como París y Londres, dada su cercanía cultural e histórica con esos lugares.

Un rasgo simbólico que sobresale en este segmento es el uso de tarifas bajas compradas entre semana, la planeación exhaustiva de los gastos y el uso de líneas aéreas canadienses que ofertan estos servicios; se inclina por el uso de los hoteles all inclusive en los que se sienta consentido y valora la distinción de éstos, de manera que es posible que la industria de los hoteles boutique pueda ser apreciada por él. Su interés se centra en actividades de turismo cultural y de naturaleza, sin embargo prefiere alojarse en hostales y hoteles de tres estrellas, aunque habría que observar la clara tendencia hacia el hospedaje en hoteles todo incluido; lo cual se infiere por la capacidad económica de la moneda.

Aun cuando el uso de internet se ha generalizado, la mayoría de los canadienses emplea el servicio de agencias de viajes. Son muy sensibles al buen trato, y cuidan los detalles de la planeación, los precios y servicios que deberán ser diseñados en función de sus necesidades, ya que si fueran comparados con los estadounidenses se ofenderían, por lo tanto es necesario conocerlos para atenderlos. Estas características se constituyen en un aspecto simbólico que conforma su identidad. Los canadienses de Quebec prefieren visitar Europa y el Mediterráneo, mientras que el resto preferiría conocer destinos en el continente americano, cuestión simbólica de legitimación de la práctica turística entre los francocanadienses, que aspiran a regresar a las regiones que los conecten con su identidad histórica.A diferencia de los estadounidenses, expresan que su principal motivo es el descanso en las tranquilas playas de Cozumel, así como conocer la cultura del destino, adentrándose en la gastronomía y disfrutando de atardeceres en el malecón en convivencia con los residentes. Puesto que viajan en pareja y la mayoría son de edad adulta, comentan que prefieren realizar actividades como el snorkel, el cual se puede practicar con facilidad en convivencia familiar. 


\section{Conclusiones}

A partir del análisis, se concluye que las corrientes turísticas internacionales a Cozumel no son homogéneas, por lo que se propone el replanteamiento de estrategias de comercialización, no sólo en función de la obtención de datos, sino de una metodología integral que permita la interpretación de los perfiles, conociendo en profundidad la descripción de sus características y las necesidades intrínsecas que se expresan mediante sus prácticas en el viaje.

El examen indica que el turista internacional que visita Cozumel convive y experimenta sensaciones de satisfacción y bienestar al relacionarse con los residentes del destino, tanto en su rol de prestadores de servicios turísticos como de nativos interactuando en el mismo espacio social, de manera que es importante conocer cómo se relacionan y sus efectos en los grupos sociales. Aún quedan muchas brechas abiertas para posteriores investigaciones que irán interrelacionándose, con el fin de hacer de Cozumel un destino que permita ser manejado con base en la certeza del conocimiento de su cultura, sus grupos sociales, su economía y las significaciones tanto para los turistas como para los habitantes.

La existencia de una distinción entre las prácticas de estos grupos de viajeros se reconoce como legítima. El turista norteamericano es identificado por los actores sociales como aquel que se ha convertido en un símbolo del turismo internacional y para el cual el Estado ha dispuesto a la sociedad y ha creado una estructura y superestructura, legitimando lo que hace, consume, usa y propone, sin necesidad de ser cuestionado. Los implicados en este campo cultural corresponden a un grupo en el cual son reconocidos por pertenecer, de modo que las acciones individuales que se deriven del grupo serán respaldadas por él, lo que se convierte en un capital que otorga poder con relación a otras personas o grupos de referencia.

\section{FUENTES CONSULTADAS}

Bourdieu, P. (1991). La distinción. Madrid:Taurus. (1997). Razones prácticas. Barcelona:Anagrama. (200I). Capital cultural, escuela y espacio social. México: Siglo XXI Editores. 
Degl' Innocenti, M. (2007).“Pierre Bourdieu:El capital cultural y la reproducción social”. Disponible en: http://www.unlz.edu.ar/catedras/s-pedagogia/ artic3.htm [2007, I 3 de abril].

Pavón Santana, S. (1999). "Determinación de la práctica turística en Oaxaca a partir del capital cultural", en N. Monterroso Salvatierra y G.U. Valencia. Turismo y cultura. Toluca: Universidad Autónoma del Estado de México, I5I-I58.

Schuller,T.(2000)."Social and Human Capital:The Search for AppropriateTechnomethodology”. Policy Studies, 2 I (I), 25-35.

Sedetur (2009). Indicadores turísticos 2008. Chetumal:Secretaría de Turismo del Estado de Quintana Roo.

Weber, M. (1964). Economía y sociedad. México: Fondo de Cultura Económica. Zizumbo Villarreal, L. (1999). "Condición de clase y disposición estética: las clases y la idea del gusto en Bourdieu”, en N. Monterroso Salvatierra y G.U.Valencia. Turismo y cultura. Toluca: Universidad Autónoma del Estado de México, 103-126. 